\title{
ILHA DE CALOR URBANA EM CIDADE DE PEQUENO PORTE E A INFLUÊNCIA DE VARIÁVEIS GEOURBANAS
}

\author{
ALVES, Elis Dener Lima - elis.alves@ifgoiano.edu.br \\ Instituto Federal de Educação, Ciência e Tecnologia Goiano / IF GOIANO
}

\begin{abstract}
RESUMO: O objetivo da presente pesquisa foi de analisar a variabilidade temporal e espacial das ilhas de calor urbanas (ICU) em Iporá - Goiás (32218 habitantes) e verificar a influência das variáveis geourbanas na determinação das ICU. Para tanto, foram instalados oito termo-higrômetros na área urbana de Iporá. Nas análises de dados utilizou-se a técnica de regressão linear múltipla. Os resultados evidenciaram que a ilha de calor na cidade de Iporá apresenta configuração espacial e temporal diferentes das grandes cidades. As intensidades e os padrões térmicos tendem a ser menores. Destacase também que: 1 - A análise das diferenças térmicas entre os pontos de coleta revelou que as ICU foram mais frequentes na intensidade $0,5^{\circ} \mathrm{C}$ e $1^{\circ} \mathrm{C}$, totalizando $76 \%$ do número de ocorrências registradas para todo o período. 2 - Os padrões da ICU foram semelhantes durante o dia e durante a noite. 3 - As ilhas de calor $<2{ }^{\circ} \mathrm{C}$ ocorreram na mesma proporção durante o dia e durante a noite.4 - A Ilha de Calor Máxima (ICUmax) observada foi de $3,5^{\circ} \mathrm{C}$, ocorrendo cinco vezes. 5 - O Normalized Difference Vegetation Index (NDVI) e Índice de Urbanização (IU) foram as variáveis que mais contribuíram para explicar a variabilidade da ICU máxima. 6 - Foi observada que uma área localizada no sudoeste da cidade de Iporá - centro da cidade, apresentou frequentemente a ICU máxima. 7 - Observou-se que as áreas localizadas nos fundos de vale apresentaram os menores valores térmicos, o que sugere uma drenagem de ar frio. 8 - Durante a ocorrência de ICUmax constatou-se que as classes de ICU $>1{ }^{\circ} \mathrm{C}$ tiveram área de 14,91 $\mathrm{km} 2$, o que corresponde a $90 \%$ da área urbana.
\end{abstract}

Palavras- chaves: Clima urbano; Regressão linear múltipla; Cidades pequenas.

ISLA DE CALOR URBANA EN CIUDAD PEQUEÑA Y LA INFLUENCIA DE VARIABLES GEOURBANAS

RESUMEN: El objetivo del presente estudio fue analizar la variabilidad temporal y espacial de las islas de calor urbanas (ICU) en Iporá - Goiás y verificar la influencia de las variables geourbanas en la determinación de las ICU. Para eso, fueron instalados ocho termohigrómetros en el área urbana de Iporá. En los análisis de datos fue utilizada la técnica de regresión lineal múltiple. Los resultados mostraron que la isla de calor en la ciudad de Iporá presenta configuración espacial y temporal diferentes de las grandes ciudades. Las intensidades y los estándares térmicos tienden a ser menores. Podemos destacar también que: 1 - El análisis de las diferencias térmicas entre los puntos de recolección reveló que las ICU fueron más frecuentes en la intensidad $0,5^{\circ} \mathrm{C}$ y $1^{\circ} \mathrm{C}$, alcanzando $76 \%$ del número de ocurrencias registradas para todo el período. 2 - Los estándares de las ICU fueron semejantes durante el día y durante la noche. 3 - Las islas de calor $<2{ }^{\circ} \mathrm{C}$ ocurrieron en la misma proporción durante el día y durante la noche.4 - La isla de calor máxima (ICUmax) observada fue de 3,50 , ocurriendo cinco veces. 5 - Las variables geo urbanas NDVI e IU fueron las variables que más contribuyeron para explicar la variabilidad de la ICU máxima. 6 - Se observó que un área localizada en el sudoeste de la ciudad de Iporá - centro de la ciudad, presentó frecuentemente la ICU máxima. 7 - Se observó que las áreas ubicadas en los fondos de valle presentaron los menores valores térmicos, lo que sugiere un drenaje de aire frío. 8 - Durante la ocurrencia de ICUmax fue constatado que las clases de ICU $>1^{\circ} \mathrm{C}$ tuvieron un área de $14,91 \mathrm{~km} 2$, lo que corresponde a $90 \%$ del área urbana.

Palabras clave: Clima urbano; Regresión lineal múltiple; Ciudades pequeñas.

SMALL-SIZED URBAN HEAT ISLANDS CITIES AND THE URBAN-GEOGRAPHICAL VARIABLES INFLUENCE 
ABSTRACT: The purpose of the given essay was to render analysis upon urban heat islands (UHI) in its temporal and spatial variability held in Iporá - State of Goias and to ascertain the urban-geographical variables towards UHI scrutinization. Therefore, eight thermo-hygrometers were installed over urban area of Iporá. As per the data analysis, a multiple linear regression technique was held. The accrued results highlighted that Ibiporá heat island city feature certain discrepancies between spatial and temporal settings from other big cities. The intensities and thermal patterns tend to be smaller. It is also noteworthy the following: 1- The discrepancies analysis and thermal patterns between the collection points revealed that UHI were frequent from $0,5^{\circ}$ and $1^{\circ} \mathrm{C}$, totaling $76 \%$ from the recorded events during all timeframe. 2 - The UHI patterns were similar during the day and night. The heat islands $<2{ }^{\circ} \mathrm{C}$ occurred under the same proportion during the day and night. 4 - The heat island peak (ICUmax) value was $3,5^{\circ} \mathrm{C}$, peaking five times. 5 - The NVDI and IU variables were the ones which mostly added in order to attest the UHI peak. 6 - It was observed that an area located in the Southwest of Iporá city - the downtown, showed the highest UHI peak on a frequent basis. 7 - It was observed that the bottom-valley areas showed lower thermal values, which indicates cold air drainage. 8 - During UHImax event, it was found that $>1^{\circ} \mathrm{C}$ UHI classes had an area of $14,91 \mathrm{~km} 2$, which corresponds to $90 \%$ of the urban area.

Keywords: Urban climate; multiple linear regression; small-sized cities

\section{INTRODUÇÃO}

O desenvolvimento urbano ocorrido durante o século 20 modificou significativamente as características físicas das cidades, produzindo grande alteração no ambiente natural. Assim, as grandes áreas urbanas perderam o "equilíbrio" ecológico com o meio ambiente.

Atualmente, um dos maiores problemas sobre as áreas urbanas é a perturbação das características da atmosfera urbana. Os principais motivos, segundo Acero et al. (2012), são: (a) impermeabilização das superfícies naturais, devido à introdução de materiais artificiais; (b) presença de novos obstáculos interagindo com o fluxo de ar e (c) emissões de partículas e poluentes.

Como resultado da alteração das propriedades da cobertura da superfície, modificações térmicas, radiativas e aerodinâmicas podem ocorrer (OKE, 1987). Os dois mais significativos fenômenos associados ao clima urbano são uma alteração dos ventos locais e turbulência e um aumento na temperatura. Em áreas densamente construídas e com pouca vegetação, têm se observado que a temperatura do ar apresenta valores superiores aos da área rural (CHANG; GOH, 1999; MEMON; LEUNG; LIU, 2009; MONTÁVEZ; RODRÍGUEZ; JIMÉNEZ, 2000; SHASHUA-BAR et al., 2010; TING, 2012).

Essa tendência em ocorrer aumento da temperatura do ar da área rural para o centro das cidades, por sua configuração espacial, caracteriza o fenômeno conhecido como ilha de calor urbana (OKE, 1981; SOUCH e GRIMMOND, 2006; MEMON, et al., 2009; GARTLAND, 2010).

Em 1833, Luke Howard hipotetizou que o excesso de calor nas cidades era causado, no verão, devido à maior absorção da radiação solar pelo conjunto de superfícies verticais da cidade e à falta de umidade disponível para evaporação (GARTLAND, 2010). As teorias de Howard eram surpreendentemente precisas. 
Entretanto, existem várias outras razões que justificam o fenômeno das ilhas de calor: calor urbano gerado a partir do aquecimento; arrefecimento; transporte e processos industriais (GARTLAND, 2010); edifícios diminuem a velocidade média dos ventos, o que atrasa a transferência de energia das superfícies para o ar (ALCOFORADO et al., 2006; SZÜCS, 2013); a poluição do contribui porque as partículas no ar absorvem e emitem energia térmica para as superfícies da cidade (GRIMMOND et al., 2002; OKE, 1987).

As cidades, portanto, podem gerar um clima próprio, denominado de clima urbano. Os fatores geourbanos são os responsáveis por esta modificação em escala local. Podendo variar de acordo com o grau de urbanização da cidade ou mesmo da complexa interação entre estes fatores. Nas grandes cidades, estudos sobre essa temática têm sido elaborados secularmente. Nas últimas décadas, tem-se observado estudos dessa natureza em cidades de pequeno e médio porte.

Entretanto, quando se faz uma seleção dos estudos sobre o clima urbano, verifica-se que nas regiões e/ou ambientes mais afastados dos grandes centros de pesquisa o conhecimento nessa temática é escasso. Os estudos sobre as variações termo-higrométricas nas áreas urbanas são antigos, porém, a grande maioria está focada nas grandes cidades, por apresentarem variações mais evidentes nos padrões dos elementos meteorológicos. Pouco se conhece sobre as características do clima urbano nas cidades de médio, e, principalmente, nas de pequeno porte (ALVES; SPECIAN, 2010a).

Existem alguns estudos de climatologia para a cidade de Iporá, a maioria destes são oriundos dos trabalhos de conclusão de curso. Tais estudos contribuíram, até certo ponto, para o entendimento de padrões, notadamente, no campo termodinâmico e hidrometeorológico.

A primeira publicação sobre o aspecto do clima urbano foi de Alves e Specian (2009), neste artigo os autores buscaram verificar a existência de variações térmicas e higrométricas em quatro pontos de coleta na área urbana de Iporá-GO, estes pontos se diferenciavam basicamente no uso e ocupação do solo. Neste estudo foi possível observar que, independentemente do período de coleta, os pontos localizados nas áreas mais urbanizadas apresentaram temperaturas mais elevadas, configurando nestes locais ilhas de calor, este estudo foi um dos pioneiros a cerca do campo termodinâmico em Iporá.

O trabalho de Alves e Specian (2010a) teve como objetivo investigar os padrões da temperatura do ar e da umidade relativa, a fim de se identificar possíveis anomalias termo-higrométricas no espaço intra-urbano de Iporá. Os resultados evidenciaram que existe uma lógica espacial da temperatura e da umidade, e que essa acompanha os tipos de uso e ocupação do solo. Verificouse também a presença de ilhas de calor na magnitude de $2,8^{\circ} \mathrm{C}$ de intensidade e ilhas secas na magnitude de $8 \%$.

O estudo de Specian, Silva Junior e Vecchia (2013) analisou a variação dos valores de temperatura do ar e umidade relativa para dois pontos distintos no interior do sítio urbano de Iporá, o primeiro ponto foi em uma praça e o segundo em área remanescente de cerrado. Os resultados mostraram variação de até $4^{\circ} \mathrm{C}$ de temperatura entre os dois pontos, sendo que o ponto 2 mantevese sempre com a temperatura menor. A umidade relativa do ar apresentou 
variação máxima de $19 \%$ entre os pontos de coleta, com maiores valores para o remanescente de cerrado.

A pesquisa de Oliveira e Alves (2013) verificou os padrões da temperatura e da umidade entre duas praças públicas de Iporá, que se diferenciavam pela densidade de vegetação. Os resultados mostraram que a praça com vegetação arbórea obteve os menores valores de temperatura e os maiores de umidade, registrando diferenças térmicas de $6,3^{\circ} \mathrm{C}$ e higrométricas de $21 \%$, às 15 horas. O estudo concluiu que a vegetação arbórea nas praças públicas desempenha função importante, pois ameniza os efeitos do clima urbano. Resultados semelhantes foram obtidos por Siqueira, Oliveira e Alves (2013).

O objetivo da pesquisa de Alves e Vecchia (2014) foi de analisar a influência dos atributos geourbanos na configuração dos padrões da temperatura de superfície em Iporá. O método de análise consistiu em analisar as contribuições das variáveis em explicar os padrões da temperatura de superfície. Os resultados evidenciaram que as variáveis NDVI (Normalized Difference Vegetation Index) e IU (Índice de Urbanização) conseguiram explicar cerca de $60 \%$ da variabilidade. Outro resultado foi que o modelo de regressão conseguiu representar os padrões da TS (Temperatura de Superfície) com precisão adequada, mesmo tratando-se de estudo experimental.

Entretanto, estes estudos tiveram caráter identificativo, sendo necessários estudos mais aprofundados sobre o campo termodinâmico da cidade de Iporá.

Dessa forma, o objetivo desta pesquisa foi de analisar a variabilidade temporal e espacial das ilhas de calor em Iporá - Goiás e verificar a influência das variáveis geourbanas na determinação das ilhas de calor.

\section{MATERIAIS E MÉTODOS}

\section{ÁREA DE ESTUDO}

O município de Iporá localiza-se no Oeste do estado de Goiás (Figura 1), sua área territorial é de 1026,384 km2 (IBGE, 2014).

A área de estudo encontra-se na borda da Bacia Sedimentar do Paraná, sendo que parte do município foi instalada em região identificada como Arco Magmático de Goiás (NAVARRO; ZANARDO, 2007). O relevo, em partes do município, é suavemente ondulado, apresentando afloramentos desgastados do arco magmático, com vertentes mais abruptas e elevações de até $850 \mathrm{~m}$, contrastando com a média de altitude do município que é de 600 m (SPECIAN; VECCHIA, 2014). 


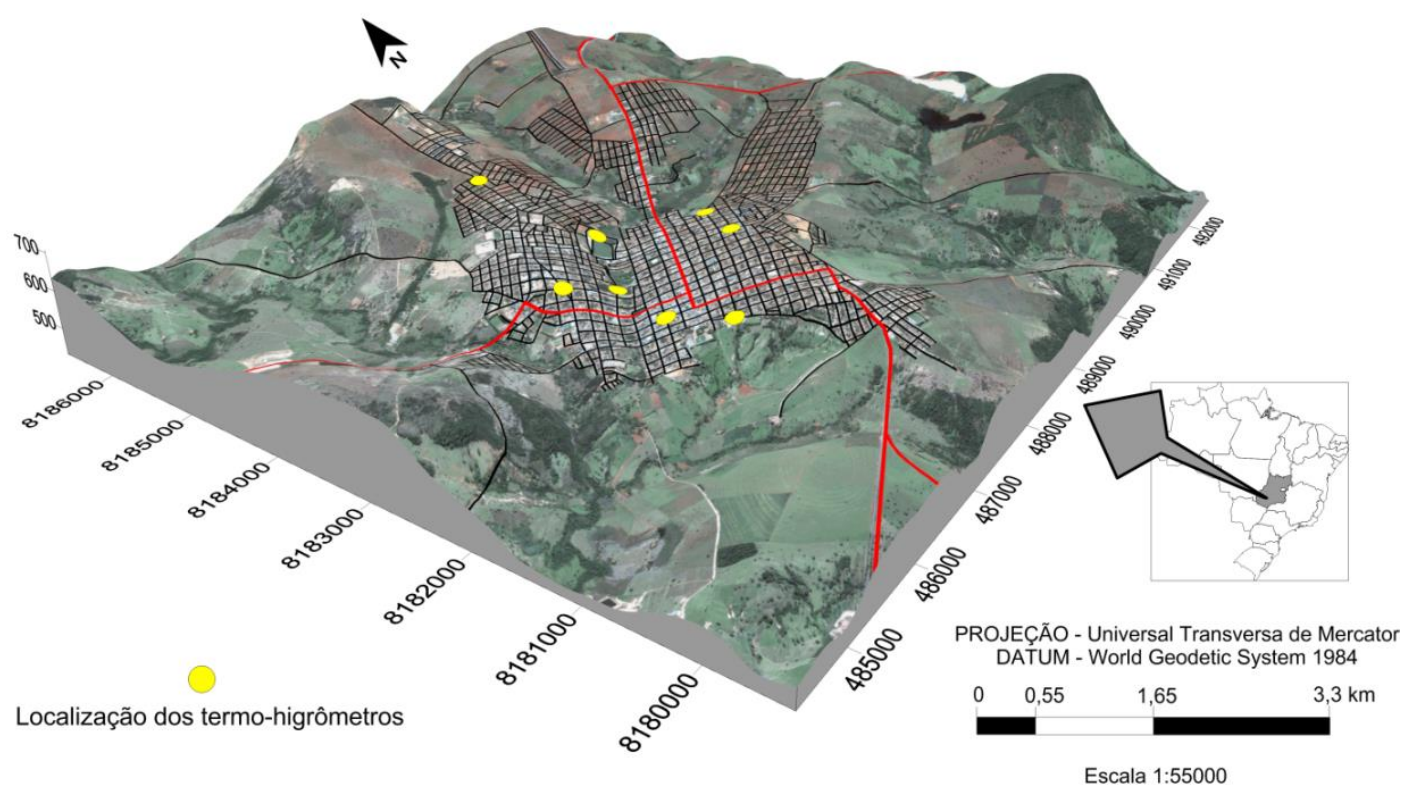

Figura 1 - Mapa de localização da cidade de Iporá.

Nas últimas décadas a população de Iporá não se alterou de forma substancial, atualmente, Iporá possui população de 32218 habitantes (IBGE, 2016). De 1980 aos dias atuais houve acréscimo de, aproximadamente, 5000 pessoas, distribuído ao longo dos anos.

A ocupação e o uso do solo seguem a lógica da própria característica do relevo, em Iporá predominam as pastagens. A economia tem sua base na pecuária de corte e de leite desenvolvidas de forma extensiva, além do comércio que atende aos outros municípios da região (SPECIAN; VECCHIA, 2014).

Nimer (1979) define o clima do estado de Goiás como Tropical SemiÚmido e que o estado e a região Centro Oeste estão sujeitos a mudanças bruscas (variação em mais de $10^{\circ} \mathrm{C}$ e chuvas intensas), ocasionadas pelo sistema de correntes perturbadas e entradas de massas de ar fria. O estudo de Alves e Specian (2008) indica que o clima de Iporá é "primeiro" úmido com moderado déficit de água no inverno e grande excesso no verão.

O clima da Região Centro Oeste é dominado por uma série de sistemas atmosféricos, destaque para massa Tropical Atlântica (mTa) que, devido à ação persistente do anticiclone do Atlântico Sul, possui atuação durante o ano todo, sendo que no inverno, o resfriamento basal aumenta a estabilidade superior, contribuindo para a ocorrência de bom tempo (STEINKE, 2004). A autora afirma ainda que durante o verão a massa Equatorial Continental (mEc) em conjunto com outros sistemas é responsável pelo aumento de umidade e chuvas na região.

\section{CÁLCULO DA ILHA DE CALOR URBANA}

Os dados apresentados referem-se ao período de coleta de 20 de outubro a 24 de novembro de 2014, com coletas de dados a cada 30 minutos. Os locais de medição da temperatura do ar podem ser observados na Figura 1. 
Não existe um critério universal para o cálculo da intensidade de ilha de calor urbana (MARTIN-VIDE; SARRICOLEA; MORENO-GARCÍA, 2015; OKE, 2006), em muitos estudos esse cálculo foi realizado subtraindo a temperatura registrada no meio urbano pela temperatura de estações meteorológicas de aeroportos. Neste trabalho, baseando-se em Andrade (2003) e Lopes et al., (2013), considerou-se que existia ICU em Iporá sempre que a temperatura de um dos locais de medição fosse superior à temperatura dos outros. A intensidade da ICU foi calculada como a diferença, num determinado momento, entre o local de maior temperatura (T_maior) e o local de menor temperatura (T_menor), conforme Equação 1.

$I C U=T_{\text {maior }}-T_{\text {menor }}$

Equação 1

\section{DEFINIÇÃO DAS VARIÁVEIS GEOURBANAS}

Com o intuito de se obter uma equação na qual se pudesse estimar os valores da ilha de calor máxima e verificar a influências das variáveis geourbanas, foram elaborados mapas das variáreis geourbanas: densidade demográfica; índice de urbanização; Altitude; orientação das vertentes; NDVI e declividade das vertentes, para toda a área urbana da cidade de Iporá - Goiás, conforme 2. A verticalização nas cidades tem-se mostrado um fator importante no clima urbano, entretanto, em cidades pequenas há pouca variação na altura dos edifícios e também pouca ou nenhuma informação sobre esta variável e, portanto, esta não foi utilizada neste estudo.

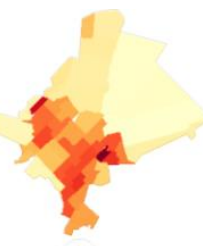

A

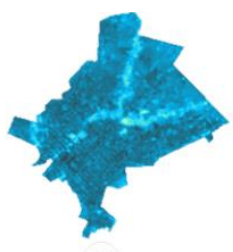

B

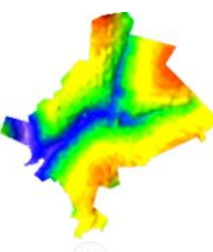

C

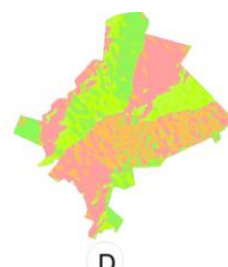

D

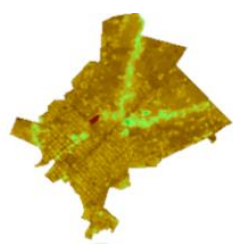

E

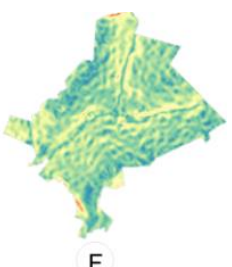

$\mathrm{F}$

Figura 2 - Variáveis geourbanas utilizadas: densidade demográfica $(A)$; índice de urbanização (B); Altitude (C); orientação das vertentes (D); NDVI (E) e declividade das vertentes $(F)$.

\section{ANÁLISE DOS DADOS}

De posse dos mapas das variáveis geourbanas foi realizada regressão linear múltipla, que consiste em uma técnica multivariada cuja finalidade principal é obter uma relação matemática entre uma das variáveis estudadas (variável dependente ou resposta) e o restante das variáveis que descrevem o sistema (variáveis independentes ou explicativas), e reduzir o número de variáveis independentes com o mínimo de perda de informação. Sua principal aplicação, depois de encontrada a relação matemática, é produzir valores para a variável dependente quando se têm as variáveis independentes (LAPPONI, 2005).

De acordo com Montgomery, Peck e Vining (2012) o modelo de regressão linear múltipla (MRLM) com k variáveis de controle pode ser representado pela Equação 2. 
$Y=\beta_{0}+\beta_{1} X_{1 i}+\beta_{2} X_{2 i}+\cdots+\beta_{k} X_{k i}+\varepsilon_{i}$

Equação 2

Os coeficientes de regressão $\beta \_0, \quad \beta \_1, \ldots, \beta \_k$ são descrito por Montgomery, Peck e Vining (2012) como: $\beta \_0$ coeficiente do intercepto, o qual corresponde à media de $Y_{\text {_i }}$ quando todas as variáveis de controle são iguais a zero; os coeficientes $\beta \_1, \ldots, \quad \beta \_k$ coeficientes de regressão parciais. 0 coeficiente $\beta \_k$ pode ser interpretado como a derivada parcial de $Y \_i$ em relação a $X \_k i$, ou seja, é a variação de $Y$ causada por uma variação unitária em $X \_k$ dado que as outras variáveis de controle sejam mantidas constantes.

Com a finalidade de verificar estatisticamente quais as variáveis independentes (variáveis geourbanas) com maior potencialidade de contribuir para o cálculo da ilha de calor máxima empregou-se a técnica de regressão linear múltipla passo-a-passo.

A regressão passo-a-passo é uma ferramenta bastante conhecida, utilizada para verificar quais as melhores variáveis independentes para uma determinada variável dependente, levando em conta apenas a dependência linear entre as variáveis. Neste tipo de análise, um modelo é desenvolvido pela inserção de uma variável independente a cada passo, a partir do conjunto total de variáveis (LAPPONI, 2005; RIBEIRO JÚNIOR, 2001). A primeira variável independente inserida será aquela que apresentar maior correlação com a variável dependente. Isto é, aquela que melhor explicar a variância. A partir daí, a cada passo, será inserida nova variável independente que assegure a representação da maior fração de variância que não foi explicada pela inserção das anteriores.

Ao longo do processo, variáveis independentes podem também ser excluídas do modelo, caso a inserção de outras, consiga explicar melhor a variância, tornando-a desnecessária. O critério adotado para entrada e saída no modelo foi o nível de significância de cada variável independente com relação à variável dependente em cada passo, o software utilizado foi o Statistica.

\section{RESULTADOS E DISCUSSÕES}

Na Figura 3 é apresentada a variação da ilha de calor (ICU) observada em Iporá, para o período de $20 / 10$ a 24/11 de 2014. Nota-se que neste período foi observado, em três dias, ICU de $3,5^{\circ} \mathrm{C}$..

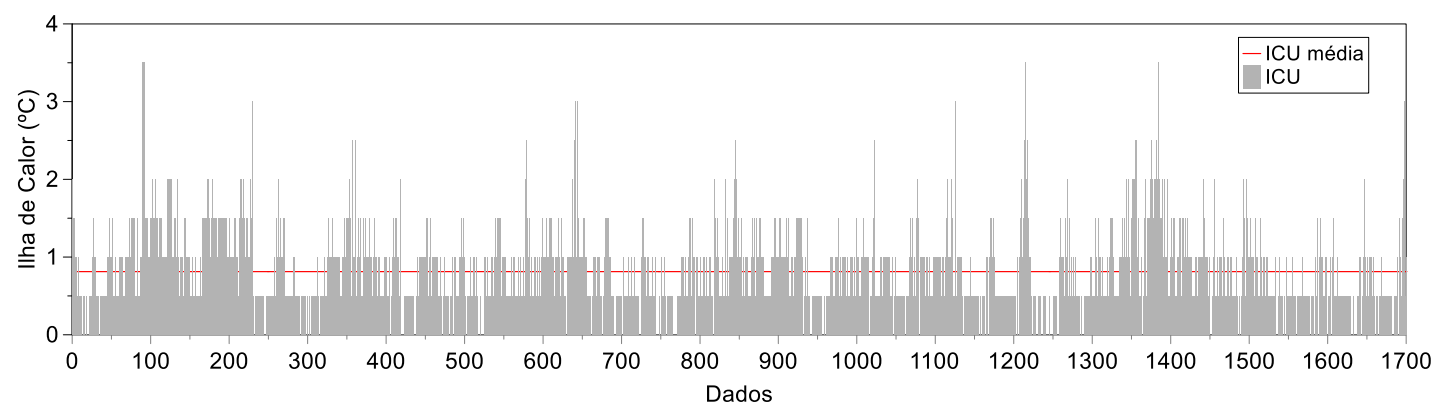

Figura 3 - Padrões da intensidade da ICU no período de 20/10 a 24/11 de 2014. 
Na Figura 4 é possível observar os padrões médios da ilha de calor em Iporá, nota-se que a maior média da ICU foi verificada às $13 \mathrm{~h}$ e $14 \mathrm{~h}$, com valor de $1,1^{\circ} \mathrm{C}$, e o maior desvio padrão foi observado às $14 \mathrm{~h}$.

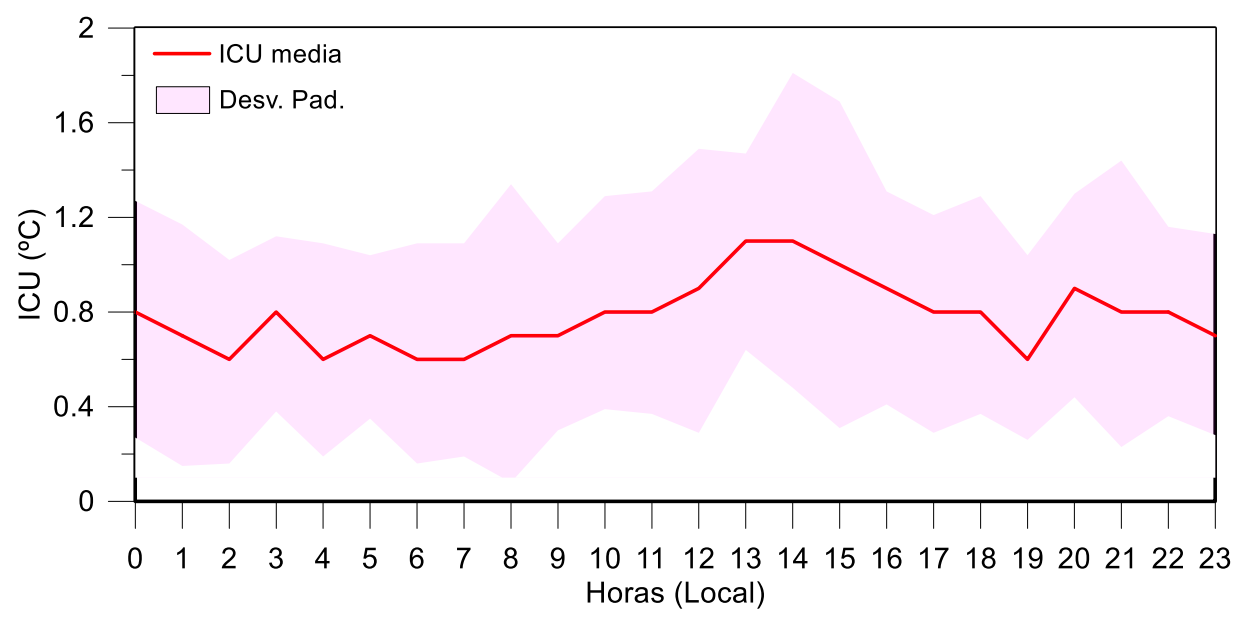

Figura 4 - Valores médios e desvio padrão das ICU.

As ICU foram mais frequentes na intensidade $0,5^{\circ} \mathrm{C}$ e $1^{\circ} \mathrm{C}$, totalizando $76 \%$ do número de ocorrências registradas. Normalmente, as ICU ocorrem em maior frequência nas classes de menores intensidades, isso já foi registrado em vários estudos (FIGUEROLA; MAZZEO, 1998; LOPES et al., 2013; MONTÁVEZ; RODRÍGUEZ; JIMÉNEZ, 2000). No horário das $22 \mathrm{~h}$ e $2 \mathrm{~h}$ da manhã ocorreram a maior quantidade de IC de $0,5^{\circ} \mathrm{C}$. Às $13 \mathrm{~h}$ foi observada elevada frequência na classe de $1^{\circ} \mathrm{C}$. ICU nas classes de $3^{\circ} \mathrm{C}$ e $3,5^{\circ} \mathrm{C}$ ocorreram poucas vezes (Figura 5).

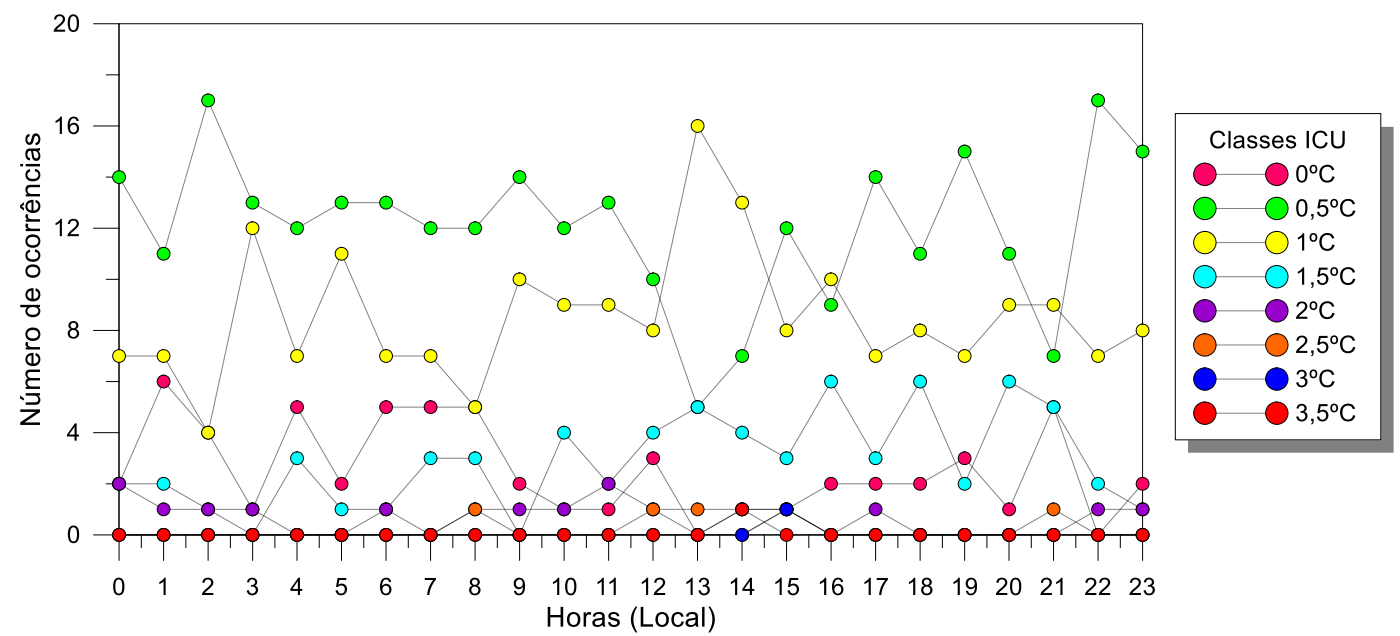

Figura 5 - Número de ocorrências horárias de Ilhas de calor.

Normalmente as maiores intensidades das ilhas de calor tendem a ocorrer em dias sem nebulosidade, e em períodos sem chuvas (ELAGIB, 2011; MOHAN et al., 2012). A água precipitada, no momento que interage com a 
superfície aquecida, começa o processo de evaporação, liberando calor latente, tornando o ar menos aquecido, portanto, a intensidade da ICU tende a ser menor. Entretanto, em Iporá, essa relação não foi evidente, conforme a Figura 6

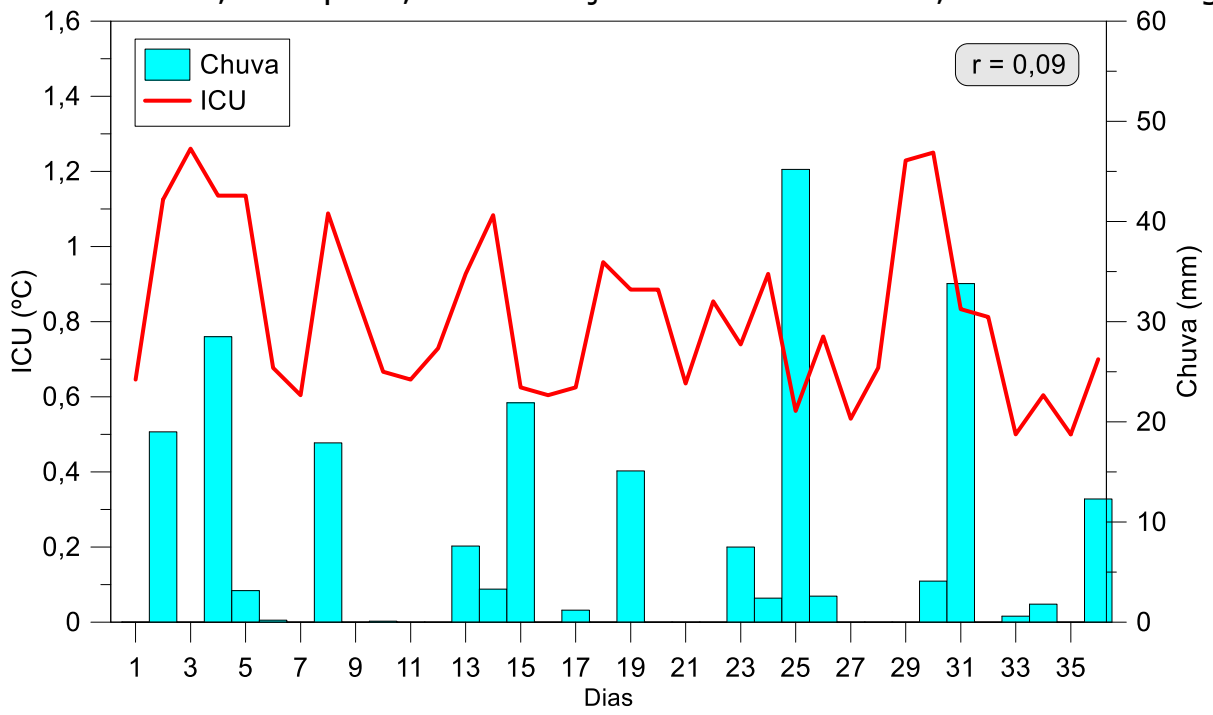

Figura 6 - Relação entre Intensidade media diária da ilha de calor e total pluviométrico diário.

A maioria dos estudos de ilhas de calor urbanas foi realizada à noite (CHANG; GOH, 1999; MIHALAKAKOU et al., 2002; MONTÁVEZ; RODRÍGUEZ; JIMÉNEZ, 2000; SANTAMOURIS, 2007), relativamente, poucos estudos têm enfocado ilhas de calor diurnas (GEORGAKIS; SANTAMOURIS; KAISARLIS, 2010; SANTAMOURIS, 2007).

Normalmente pela manhã, a diferença de temperatura entre áreas urbanas e rurais é geralmente menor. Essa diferença aumenta ao longo do dia conforme as superfícies urbanas absorvem radiação solar e a reemite em forma de ondas longas aquecendo o ar urbano. A intensidade da ilha de calor é geralmente mais elevada à noite, uma vez que as superfícies urbanas continuam a liberar calor e diminuem o arrefecimento durante o período noturno (TING, 2012).

Entretanto, os padrões das ICU foram semelhantes durante o dia e durante a noite, apresentando valores próximos, ambos os boxplots (Figura 7) obtiveram o mesmo valor máximo $\left(3,5^{\circ} \mathrm{C}\right)$, e o intervalo dos $50 \%$ dos dados do período diurno e noturno foi o mesmo $\left(0,5^{\circ} \mathrm{C}\right.$ a $\left.1^{\circ} \mathrm{C}\right)$, apenas o valor mediano foi diferente, $1^{\circ} \mathrm{C}$ para o dia e $0,5^{\circ} \mathrm{C}$ para a noite. 


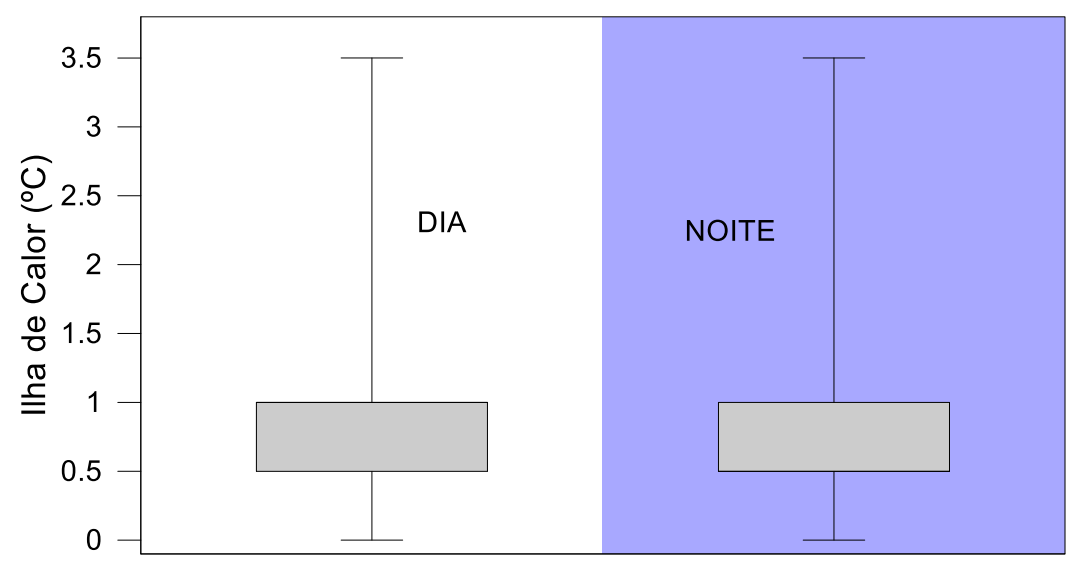

Figura 7 - Ilha de calor durante o dia e durante a noite no período de 20/10/2014 a 24/11/2014. O intervalo horário do período diurno foi definido das $7 \mathrm{~h}: 30 \mathrm{~min}$ às 19h:30min e noturno das 20h:00 às 7h:00 (hora local).

As ilhas de calor $<2^{\circ} \mathrm{C}$ ocorreram, praticamente, na mesma proporção durante o dia e durante a noite $(51,5 \%$ e $48,5 \%)$. Enquanto que as ICU $>2{ }^{\circ} \mathrm{C}$, foram, significativamente, mais frequentes durante o dia $(68,8 \%)$ que a noite $(31,2 \%)$, conforme Figura 8.

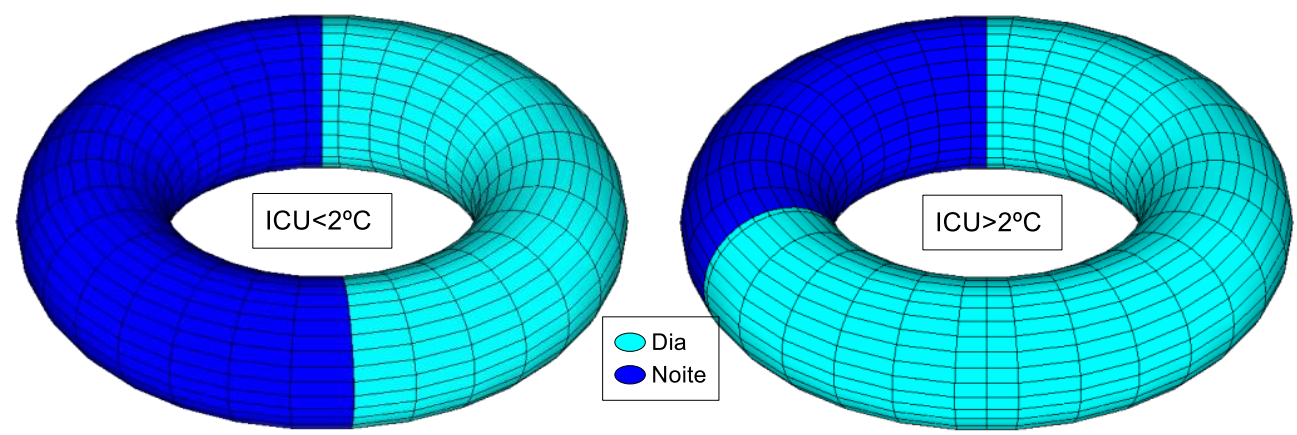

Figura 8 - Ocorrências de ICU $<2{ }^{\circ} \mathrm{C}$ e ICU $>2{ }^{\circ} \mathrm{C}$ durante o dia e durante a noite

\section{CARACTERÍSTICAS DAS ILHAS DE CALOR MÁXIMAS (ICUMAX)}

A ilha de calor máxima (ICUmax) observada foi de $3,5^{\circ} \mathrm{C}$ e ocorreu em cinco momentos, em três dias (21 de outubro, 14 e 18 de novembro de 2014). Conforme Figura 9 as ICUmax do dia 21/10 ocorreram no horário das $20 \mathrm{~h} 30 \mathrm{~min}, 21 \mathrm{~h}$ e $21 \mathrm{~h} 30 \mathrm{~min}$. Enquanto que no dia $14 / 11$ ocorreu à tarde $(14 \mathrm{~h})$ e no dia $18 / 11$ no horário das 02 h30min. 


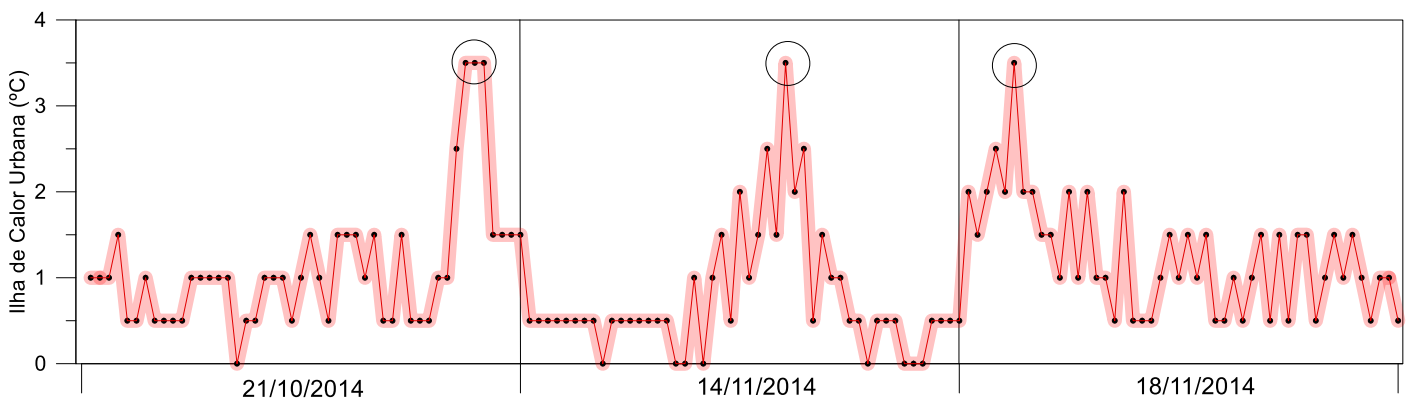

Figura 9 - Padrão da ilha de calor máxima no dia 21/10, 14/11 e 18/11 de 2014.

Nos dias de ocorrência das $\mathrm{ICU}_{\max }$ o valor máximo da temperatura do ar foi de $34,1^{\circ} \mathrm{C}$ no dia 21 de outubro (Figura ). Houve precipitação no final do dia 21, assim como, no dia 14 de novembro, com tendência a homogeneização das variáveis: temperatura do ar, umidade relativa, pressão atmosférica, e ausência de radiação durante sua ocorrência. A a amplitude térmica foi pequena, com valores de temperatura do ar baixos e umidade relativa elevada. No dia 18/11 a temperatura esteve elevada, a umidade relativa baixa e uma área maior na curva da radiação solar. Esses padrões térmicos e higrométricos são oriundos das diferentes massas de ar atuantes.

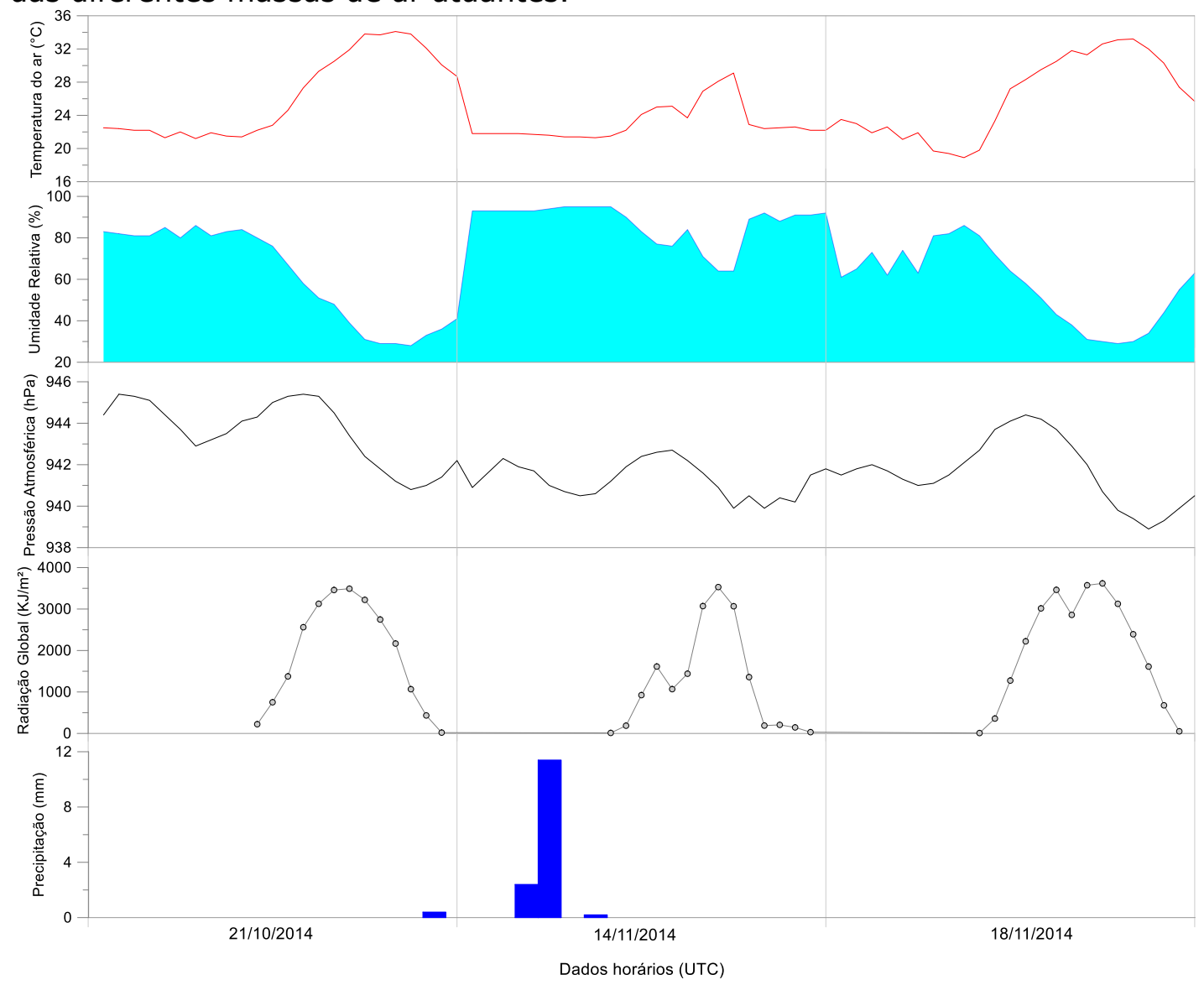

Figura 10 - Variação dos dados meteorológicos da estação automática de Iporá do INMET nos dias de ocorrência de ICU max $_{\text {. }}$ 
Na Figura 11A observa-se que a Zona de Convergência Intertropical (ZCIT) oscilou em torno de $08^{\circ} \mathrm{N} / 10^{\circ} \mathrm{N}$ no Pacífico e em torno de $07^{\circ} \mathrm{N} / 09^{\circ} \mathrm{N}$ no Atlântico. Observa-se que parte do continente foi influenciado por uma circulação anticiclônica (entre $05^{\circ}-20^{\circ} \mathrm{S}$, aproximadamente), cujo centro não esteve bem definido. No dia 14/11/14 (Figura 11B) a ZCIT oscilou em torno de $08^{\circ} \mathrm{N} / 10^{\circ} \mathrm{N}$ no Pacífico e no Atlântico e nota-se escoamento confluente entre o norte de Mato Grosso, sul de Tocantins, norte de Goiás, sul da Bahia, Minas Gerais, que foi favorecido pela difluência em altitude e favorecem a formação de áreas de instabilidade. Na Figura $11 \mathrm{C}$ verifica-se um centro ciclônico em Rondônia e outro entre o nordeste de Goiás e o sudeste de Tocantins, que gerou convergência de massa de ar e consequente levantamento do ar, formando nebulosidade. A ZCIT oscilou em torno de $08^{\circ} \mathrm{N} / 09^{\circ} \mathrm{N}$ no Pacífico e em torno de $07^{\circ} \mathrm{N} / 08^{\circ} \mathrm{N}$ no Atlântico (VIDAL, 2014).
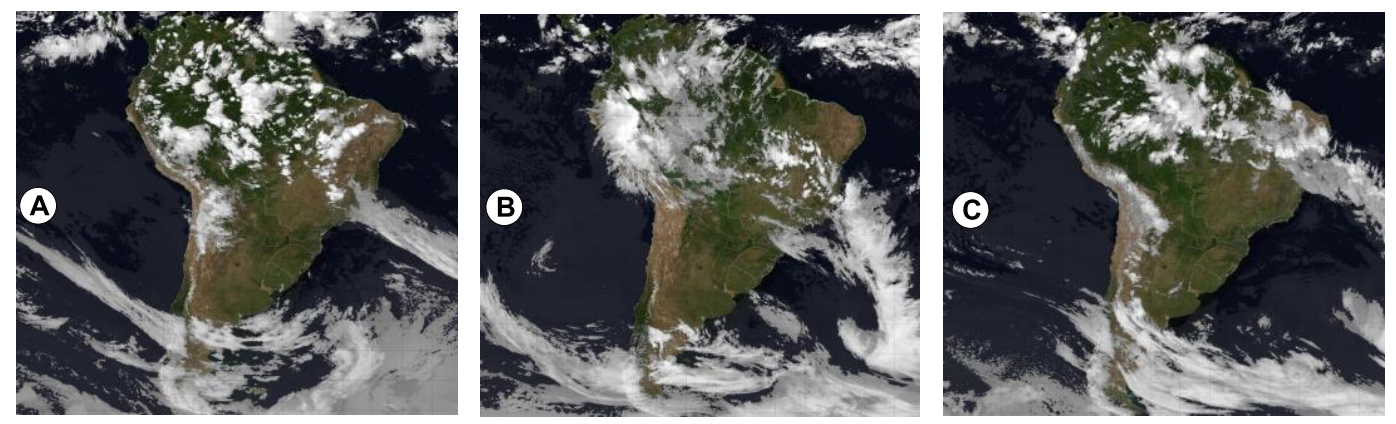

Figura 11- Atuação de massas de ar no dia 21/10/ (A), no dia 14/11 (B) e 18/11 (C) de 2014;Fonte: (INPE, 2014).

\section{REGRESSÃO LINEAR MÚLTIPLA DAS ILHAS DE CALOR MÁXIMAS}

Com o intuito de se observar o padrão da ICU durante sua ocorrência de maior intensidade, calculou-se as regressões lineares múltiplas referentes ao horário das 20h30min, $21 \mathrm{~h}$ e $21 \mathrm{~h} 30 \mathrm{~min}$ do dia 21/10/2014. Na Tabela 1 tem-se a contribuição de cada variável geourbana para explicar a variabilidade da $\mathrm{ICU}_{\max }$. As variáveis NDVI e IU estiveram presentes nas três equações (Equação 3, Equação 4 e Equação 5) e foram as variáveis mais influentes. Na Equação 3 o NDVI explicou 92,3\% da variabilidade espacial da ilha de calor das 20h30min, o IU na Equação 4 contribuiu com $86,5 \%$ e na Equação 5, correspondente às $21 \mathrm{~h} 30 \mathrm{~min}$, explicou $88,4 \%$ da variabilidade da ilha de calor. Todas as equações tiveram $r^{2}>0,9$ 
Tabela 1 - Contribuição de cada variável no padrão das ilhas de calor urbana máxima.

\begin{tabular}{cccc} 
Equação & Variáveis & $\mathbf{r}^{\mathbf{2}}$ & Influência (\%) \\
\hline \multirow{2}{*}{ Equação 3 } & NDVI & 0,923 & 92,36 \\
& NDVI, IU & 0,927 & 0,29 \\
& NDVI, IU, DD* & 0,932 & 0,53 \\
\hline \multirow{2}{*}{ Equação 4 } & IU & 0,865 & 86,5 \\
& IU, NDVI & 0,902 & 3,78 \\
& IU, NDVI, OV* & 0,908 & 0,61 \\
\hline \multirow{2}{*}{ Equação 5 } & IU & 0,884 & 88,41 \\
& IU, NDVI* & 0,925 & 4,10 \\
\hline
\end{tabular}

*Variáveis utilizadas na regressão linear múltipla $(p$-value $<0,05)$.

Equações obtidas por meio da regressão linear múltipla:

$I C U_{20 h 30 \min }=29,84+(0,0000753 \times \mathrm{DD})-(13,510 \times \mathrm{NDVI})+(0,744 \times \mathrm{IU})$

Equação 3

$I C U_{21 h}=29,741-(5,933 \times N D V I)-(0,00309 \times O V)+(6,478 \times I U)$

Equação 4

$I C U_{21 h 30 \min }=28,927-(7,302 \times N D V I)+(5,508 \times I U)$

Equação 5

O modelo semivariográfico utilizado para a krigagem da ilha de calor urbana às 20h30min (Figura 12) foi um modelo exponencial, com r2 de 0,69, com 0,06 de efeito pepita (C_0), patamar $\left(C_{-} 0+C\right)$ de 1,23 , indicando que deste ponto em diante, considera-se que não existe mais dependência espacial entre as amostras. A dependência espacial da ICU, obtida por meio do alcance (A_0), foi de $188 \mathrm{~m}$. Para a krigagem da ICU das 21h usou-se o modelo Gaussiano, com $r 2=0,78$, o efeito pepita foi de 0,48, o patamar de 1,13 e dependência espacial de 295 m, distância máxima na qual existe influência do espaço para cada ponto. Para às $21 \mathrm{~h} 30 \mathrm{~min}$ horas foi obtido 0 melhor modelo semivariográfico com $r 2$ no valor de $0,94, C$ C_0 $=0,82, C \_0+C=2,69$, a distância máxima de dependência espacial foi $758 \mathrm{~m}$. 


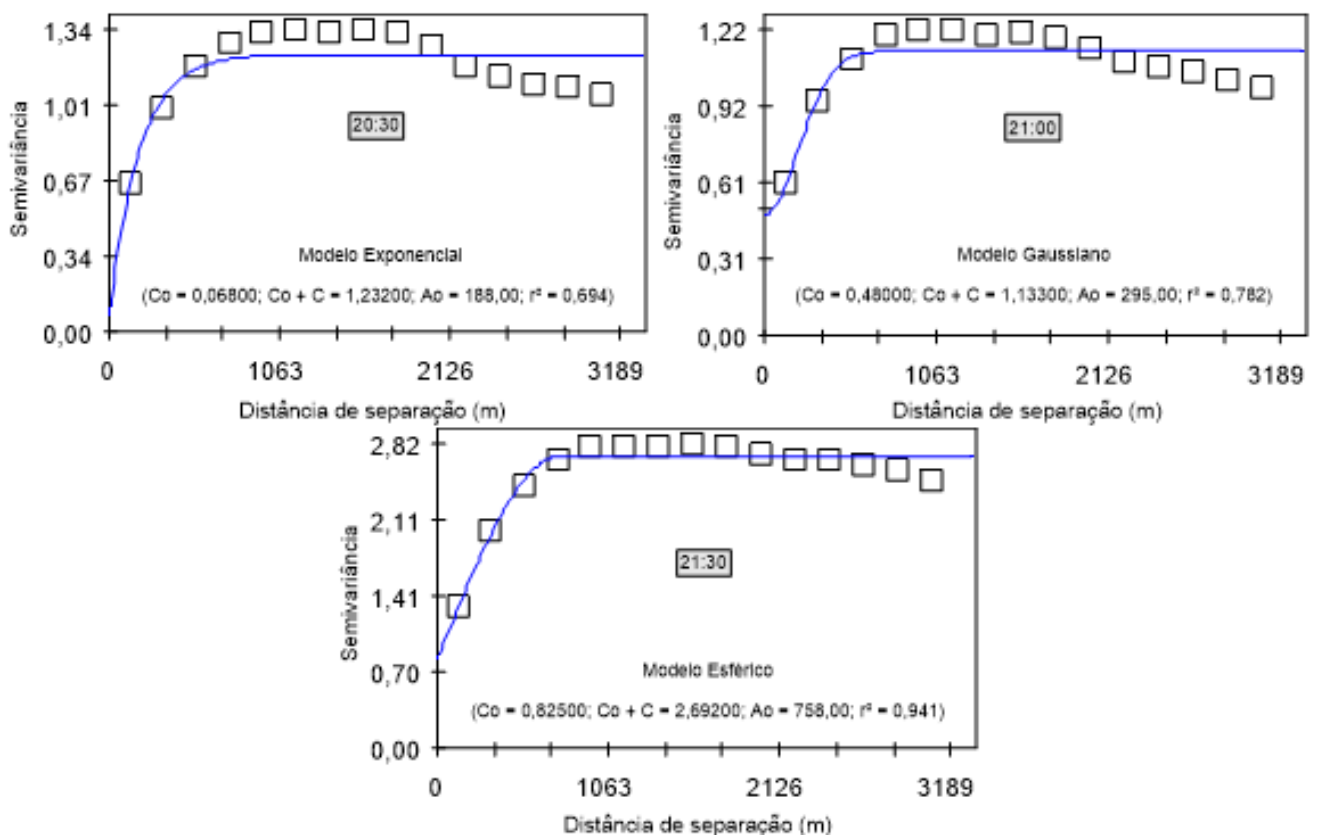

Figura 12 - Modelos de semivariogramas utilizados para krigagem das ICU.

Os modelos semivariográficos (Figura 12) foram utilizados para krigagem das ICU, os mapas resultantes podem ser observados na Figura 13. Os padrões das ICU foram semelhantes nos três horários. Nota-se que uma área localizada no sudoeste dos mapas esteve, nos três horários, com ilha de calor de forte intensidade, local correspondente ao centro da cidade de Iporá, tendo o seu pico às $21 \mathrm{~h} 30 \mathrm{~min}$. Além disso, os padrões espaciais das $\mathrm{ICU}<0$, também denominada de ilha de frescor urbana (IFU), se mantiveram

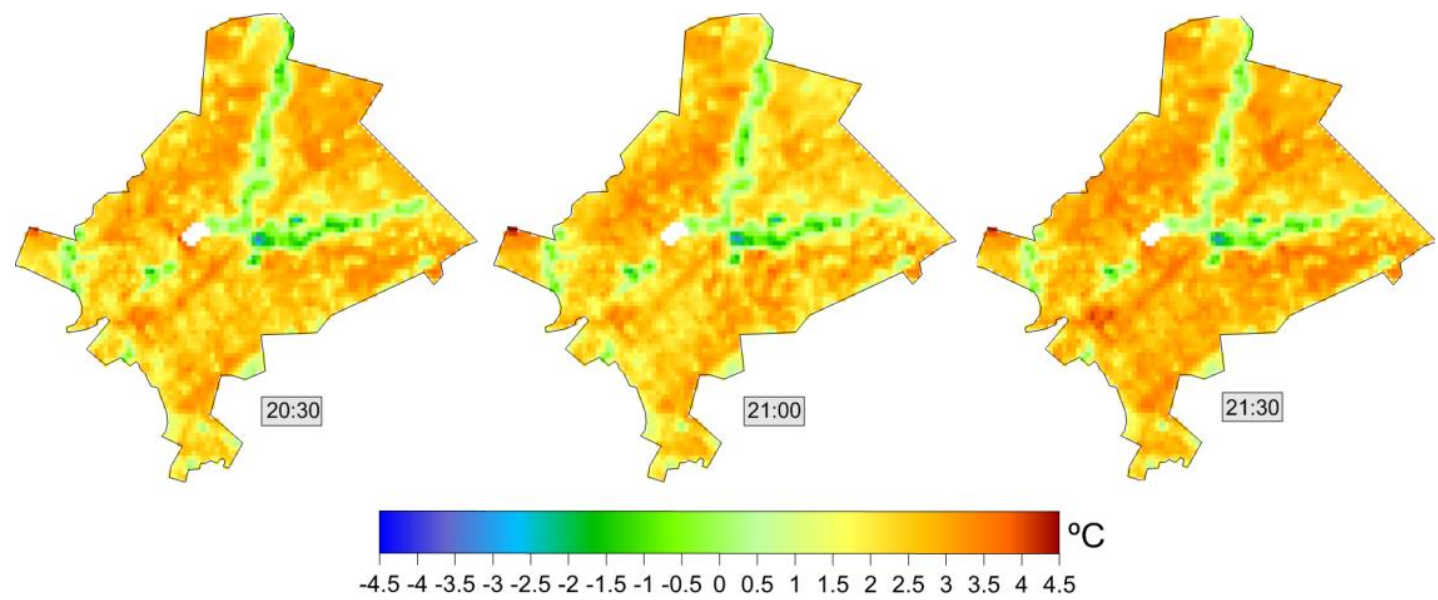

Figura 13 - Ilhas de calor urbanas estimadas no dia 21/10/14 no horário das 20h30min, $21 \mathrm{~h}$ e $21 \mathrm{~h} 30 \mathrm{~min}$.

Conforme os bloxplots da Figura 24 o maior valor da mediana foi observado na ICU das $21 \mathrm{~h} 30 \mathrm{~min}\left(2,7^{\circ} \mathrm{C}\right)$, enquanto que o valor máximo foi verificado às $21 \mathrm{~h}\left(4,5^{\circ} \mathrm{C}\right)$. Nota-se que os maiores valores correspondentes aos 
$50 \%$ dos dados foram observados às $21 \mathrm{~h} 30 \mathrm{~min}\left(2,2^{\circ} \mathrm{C}\right.$ a $\left.3^{\circ} \mathrm{C}\right)$, enquanto que às $20 \mathrm{~h} 30 \mathrm{~min}$ e às $21 \mathrm{~h}$ o intervalo foi inferior, com $1,9^{\circ} \mathrm{C}$ a $2,8^{\circ} \mathrm{C}$ e $1,8^{\circ} \mathrm{C}$ a $2,8^{\circ} \mathrm{C}$, respectivamente. Portanto, o bloxplot confirma o aumento na intensidade da ICU às $21 \mathrm{~h} 30 \mathrm{~min}$ em relação às ICU das 20h30min e $21 \mathrm{~h}$.

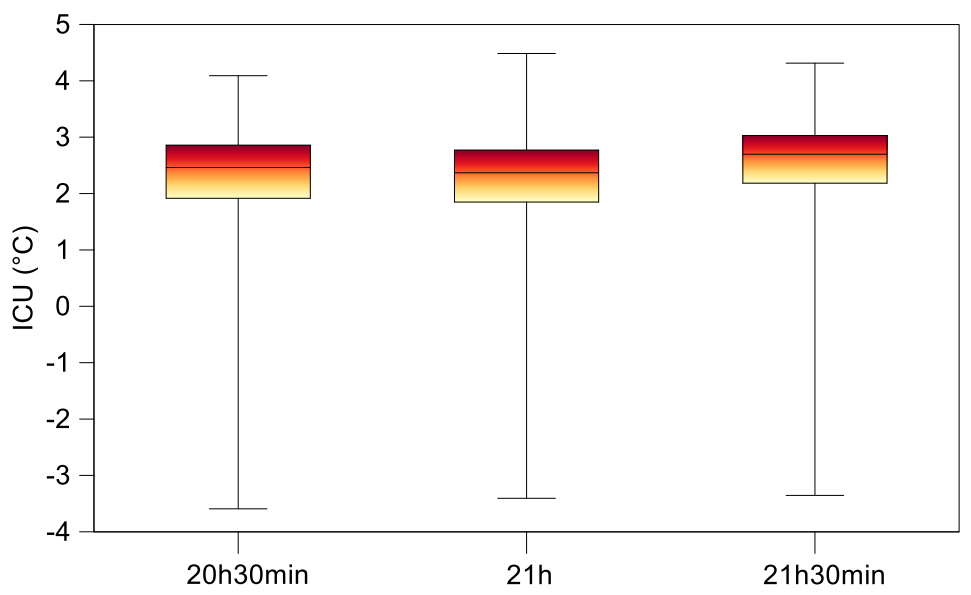

Figura 24 - Boxplot das ICU.

A ilha de calor urbana é frequentemente considerada como o fator mais importante que influencia o meio urbano e seus arredores (JAUREGUI, 1997; LOPES et al., 2013; OKE, 1973). No entanto, o fenômeno conhecido como ilha de frescor urbana também podem ocorrer nas cidades e produzir efeitos significativos. O efeito da ilha de frescor urbana foi detectado pela primeira vez por Hu, Su e Zhang (1988), com base nas análises das características do microclima de um reservatório na Região Hexi, na China.

Mesmo em momento de ocorrência de $\mathrm{ICU}_{\max }$, Podem ocorrer as ilhas de frescor, este fato pode ser observado na Figura 35 que é constituída pela sobreposição da ICU em relação a imagem do satélite Rapideye de 2011 e ao relevo em três dimensões. Observa-se que as áreas localizadas nos fundos de vale apresentaram os menores valores, o que sugere uma drenagem de ar frio, conforme o estudo de (LOPES, 1995), no qual uma das principais conclusões que se chegou foi que os lagos de ar frio em Oeiras - Portugal que se formaram nas áreas topograficamente mais deprimidas, tiveram dupla alimentação, por meio do arrefecimento do ar formado in situ, por irradiação e, por outro lado, devido ao ar frio que se formou nos setores superiores das vertentes drenado pela força da gravidade (LOPES, 1995). 


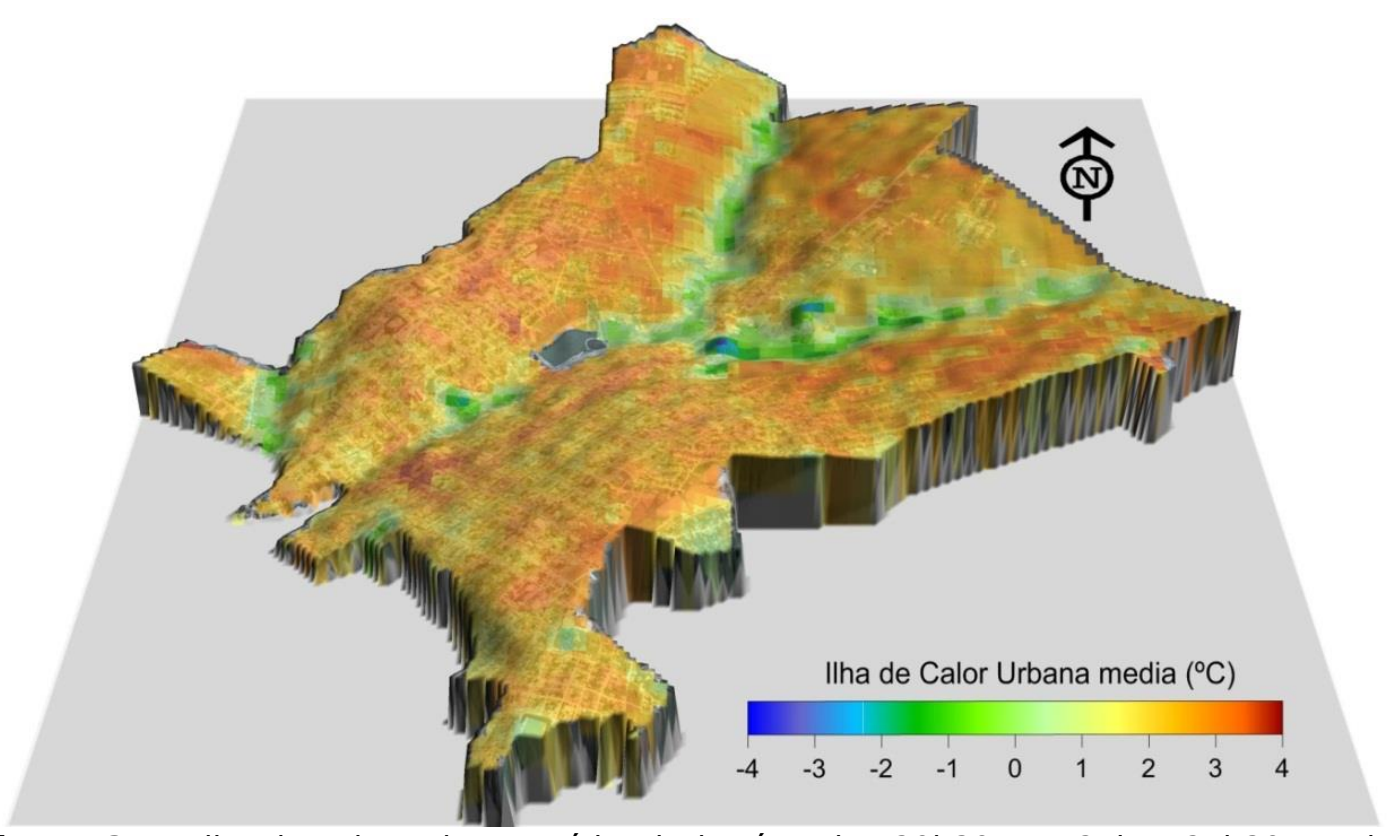

Figura 35 - Ilha de calor urbana média do horário das 20h30min, 21h e $21 \mathrm{~h} 30 \mathrm{~min}$ do dia 21/10/14.

Com o intuito de quantificar a área de cada classe de ilha de calor urbana elaborou-se a Figura 46. As classes ICU $>1{ }^{\circ} \mathrm{C}$ tiveram área de $14,91 \mathrm{~km}^{2}$, o que corresponde a $90 \%$ da área urbana. As classes de $\mathrm{ICU}<1^{\circ} \mathrm{C}$ possuíram área de $1,67 \mathrm{~km}^{2}$, que corresponde a $10 \%$ da área total. Portanto houve predominância de ilha de calor nas classes de maior intensidade. As ilhas de frescor (Classes com ICU $<0^{\circ} \mathrm{C}$ ), conforme observado na Figura 3, se concentraram nos fundos de vale, com áreas vegetadas e com corpos d'água. 

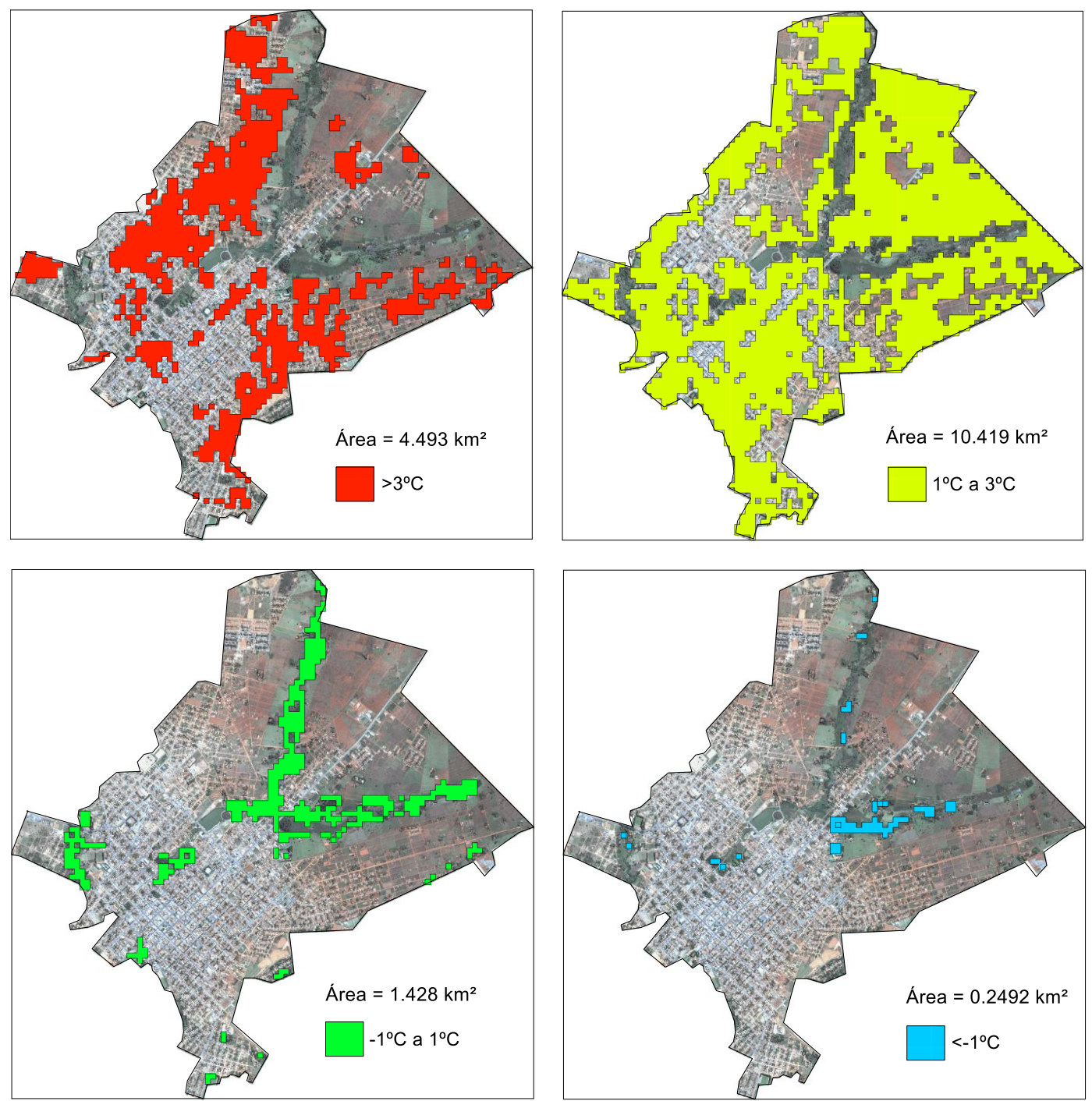

Figura 46 - Classes da Ilha de calor media do horário das 20h30min, 21h e 21h30min do dia $21 / 10 / 14$.

\section{CONSIDERAÇÕES FINAIS}

A ilha de calor em pequenas cidades apresenta configuração espacial e temporal diferentes das grandes cidades. As intensidades e os padrões térmicos tendem a ser menores. Destaca-se também que:

1 - A análise das diferenças térmicas entre os pontos de coleta revelou que as ICU foram mais frequentes na intensidade $0,5^{\circ} \mathrm{C}$ e $1^{\circ} \mathrm{C}$, totalizando $76 \%$ do número de ocorrências registradas para todo o período.

2 - Os padrões da ICU foram semelhantes durante o dia e durante a noite.

3 - As ilhas de calor $<2{ }^{\circ} \mathrm{C}$ ocorreram na mesma proporção durante o dia e durante a noite.

4 - A ilha de calor máxima ( $\mathrm{ICU}_{\max }$ ) observada foi de $3,5^{\circ} \mathrm{C}$, ocorrendo 5 vezes. 
5 - As variáveis geourbanas NDVI e IU foram as variáveis que mais contribuíram para explicar a variabilidade da $\mathrm{ICU}_{\max }$.

6 - Foi observada que uma área localizada no sudoeste da cidade de Iporá - centro da cidade, apresentou frequentemente a ICU máxima.

7 - Observou-se que as áreas localizadas nos fundos de vale apresentaram os menores valores térmicos, o que sugere uma drenagem de ar frio, conforme definido por (LOPES, 1995).

8 - Durante a ocorrência de $\mathrm{ICU}_{\max }$ constatou-se que as classes de ICU $>1^{\circ} \mathrm{C}$ tiveram área de $14,91 \mathrm{~km}^{2}$, o que corresponde a $90 \%$ da área urbana.

\section{REFERÊNCIAS BIBLIOGRÁFICAS}

ACERO, J. A. et al. Urban heat island in a coastal urban area in northern Spain. Theoretical and Applied Climatology, v. 113, n. 1-2, p. 137-154, 10 out. 2012.

ALCOFORADO, M.-J. et al. Observational studies on summer winds in Lisbon (Portugal) and their influence on daytime regional and urban thermal patterns. Merhavim, v. 6, p. 90-112, 2006.

ALVES, E. D. L.; SPECIAN, V. Caracterização do Balanço Hídrico e Clima do Município de Iporá (GO) $1^{\circ}$ Encontro de Divulgação da Produção Científica do Oeste de Goiás. Anais...Iporá: 2008.

ALVES, E. D. L.; SPECIAN, V. CONTRIBUIÇÃO AOS ESTUDOS DO CLIMA URBANO: variação térmica e higrométrica em espaços intra-urbanos. Mercator, v. 8, n. 17, p. 181-191, 31 dez. 2009.

ALVES, E. D. L.; SPECIAN, V. Estudo do Comportamento Termohigrométrico em Ambiente Urbano: Estudo de Caso em Iporá-GO. Revista Brasileira de Geografia Física, v. 02, p. 87-95, 2010 a.

ALVES, E. D. L.; SPECIAN, V. O clima intra-urbano de Iporá-GO: um estudo em episódios. Revista de Geografia, v. 27, n. 3, p. 141-154, 2010b.

ALVES, E. D. L.; VECCHIA, F. A. S. Atributos geourbanos e a temperatura de superfície: primeiros experimentosVIII SLAGF e IV SIAGF. Anais...Santiago: 2014.

ANDRADE, $\mathrm{H}$. Bioclima humano e temperatura do ar em Lisboa. [s.l.] PhD Thesis University of Lisbon, 2003.

CHANG, C.; GOH, K. The relationship between height to width ratios and the heat island intensity at 22: $00 \mathrm{~h}$ for Singapore. International Journal of Climatology, v. 19, n. 9, p. 1011-1023, jul. 1999.

ELAGIB, N. A. Evolution of urban heat island in Khartoum. International Journal of Climatology, v. 31, n. 9, p. 1377-1388, 2 jul. 2011.

FIGUEROLA, P. I.; MAZZEO, N. A. Urban-rural temperature differences in Buenos Aires. International Journal of Climatology, v. 18, n. 15, p. 17091723, dez. 1998.

GARTLAND, L. Ilhas de calor: como mitigar zonas de calor em áreas urbanas. São Paulo: Oficina de textos, 2010.

GEORGAKIS, C.; SANTAMOURIS, M.; KAISARLIS, G. The Vertical Stratification of 
Air Temperature in the Center of Athens. Journal of Applied Meteorology and Climatology, v. 49, n. 6, p. 1219-1232, 2010.

GRIMMOND, C. S. B. et al. Local-scale fluxes of carbon dioxide in urban environments: methodological challenges and results from Chicago. Environmental pollution (Barking, Essex: 1987), v. 116 Suppl , p. S24354, jan. 2002.

HU, Y.; SU, C.; ZHANG, Y. Research on the microclimate characteristics and cold island effect over a reservoir in the Hexi Region. Advances in Atmospheric Sciences, v. 5, n. 1, p. 117-126, fev. 1988.

IBGE. Base de informações do Censo Demográfico 2016: resultados da Sinopse por setor censitário. Rio de Janeiro: Centro de Documentação e Disseminação de Informações, 2016.

IBGE. Diretoria de Pesquisas, Coordenação de População e Indicadores Sociais.

<http://www.ibge.gov.br/home/estatistica/populacao/estimativa2014/>. Acesso em: 5 maio. 2015.

INPE. Boletim técnico. Disponível em: <http://tempo.cptec.inpe.br/bol_tecnico.shtml>. Acesso em: 2 jan. 2015.

JAUREGUI, E. Heat Island Development in Mexico City. Atmospheric Environment, v. 31, n. 22, p. 3821-3831, nov. 1997.

LAPPONI, J. C. Estatistica Usando Excel. 4. ed. Rio de Janeiro: CAMPUS - RJ, 2005.

LOPES, A. Drenagem e acumulação de ar frio em noites de arrefecimento radiativo. Um exemplo no vale de Barcarena (Oeiras). Finisterra, v. 30, n. 5960 , p. $149-164,1995$.

LOPES, A. et al. Lisbon Urban Heat Island Updated: New Highlights about the Relationships between Thermal Patterns and Wind Regimes. Advances in Meteorology, v. 2013, p. 1-11, 2013.

MARTIN-VIDE, J.; SARRICOLEA, P.; MORENO-GARCÍA, M. C. On the definition of urban heat island intensity: the "rural" reference. Frontiers in Earth Science, v. 3, p. $1-6,2015$.

MEMON, R. A.; LEUNG, D. Y. C.; LIU, C.-H. An investigation of urban heat island intensity (UHII) as an indicator of urban heating. Atmospheric Research, v. 94, n. 3, p. 491-500, nov. 2009.

MIHALAKAKOU, G. et al. Application of Neural Networks to the Simulation of the Heat Island over Athens, Greece, Using Synoptic Types as a Predictor. Journal of Applied Meteorology, v. 41, n. 5, p. 519-527, maio 2002.

MOHAN, M. et al. Urban Heat Island Assessment for a Tropical Urban Airshed in India. Atmospheric and Climate Sciences, v. 02, n. 02, p. 127-138, 2012.

MONTÁVEZ, J. P.; RODRÍGUEZ, A.; JIMÉNEZ, J. I. A study of the urban heat island of Granada. International Journal of Climatology, v. 20, n. 8, p. 899911,30 jun. 2000.

MONTGOMERY, D. C.; PECK, E. A.; VINING, G. G. Introduction to Linear Regression Analysis. 5. ed. [s.I.] John Wiley \& Sons, 2012. 
NAVARRO, G. R. B.; ZANARDO, A. Geoquímica de gnaisses do arco magmático de Goiás na região sul do estado de Goiás. Geologia USP - Serie Cientifica, v. 7, n. 1, p. 19-28, 2007.

NIMER, E. Climatologia do Brasil. 4. ed. Rio de Janeiro: IBGE, 1979.

OKE. City size and the urban heat island. Atmospheric Environment, v. 7, n. 8, p. 769-779, ago. 1973.

OKE, T. R. Boundary layer climates. 2. ed. [s.I.] Routledge, 1987.

$O K E, T$. R. Initial guidance to obtain representative meteorological observations at urban sites. Geneva: IOM Report No.81, WMO/TD. No. 1250, 2006.

OLIVEIRA, M. DE; ALVES, W. S. A influência da vegetação no clima urbano de cidades pequenas: um estudo sobre as praças públicas de Iporá-GO. Revista Territorial, v. 2, n. 2, p. 61-77, 2013.

RIBEIRO JÚNIOR, J. I. Análises estatísticas no SAEG. 1. ed. Viçosa: UFV, 2001.

SANTAMOURIS, M. Heat Island Research in Europe: The State of the ArtAdvances in Building Energy Research, 2007. Disponível em: <http://www.tandfonline.com/doi/abs/10.1080/17512549.2014.897252>.

SHASHUA-BAR, L. et al. Microclimate modelling of street tree species effects within the varied urban morphology in the Mediterranean city of Tel Aviv, Israel. International Journal of Climatology, v. 30, n. 1, p. 44-57, 2010.

SIQUEIRA, L. M.; OLIVEIRA, M. M. DE; ALVES, W. S. Variação termohigromética entre microclimas urbanos. Revista Visão Acadêmica, v. 4, n. 6, p. $62-80,2013$.

SOUCH, C.; GRIMMOND, S. Applied climatology: urban climate. Progress in Physical Geography, v. 30, n. 2, p. 270-27, 2006.

SPECIAN, V.; SILVA JUNIOR, U. P. DA; VECCHIA, F. A. S. Padrão térmico e higrométrico para dois ambientes de estudo: área urbanizada e remanescente de cerrado na cidade de Iporá-GO. Espaço \& Geografia, v. 16, n. 1, p. 255$277,2013$.

SPECIAN, V.; VECCHIA, F. A. S. Distribuição da frequência mensal da precipitação para região Oeste de Goiás: comparação entre dois postos pluviométricos. Ateliê Geográfico, v. 8, n. 1, p. 200-214, 2014.

STEINKE, E. T. Considerações sobre variabilidade e mudança climática no Distrito Federal, suas repercussões nos recursos hídricos e informação ao grande público. [s.l.] Universidade de Brasília, 2004.

SZÜCS, Á. Wind comfort in a public urban space-Case study within Dublin Docklands. Frontiers of Architectural Research, v. 2, n. 1, p. 50-66, mar. 2013.

TING, D. S.-K. Heat Islands - Understanding and Mitigating Heat in Urban Areas. [s.I.] Earthscan LLC, 2012.

VIDAL, C. Boletim técnico: análise sinótica. Disponível em: <http://tempo.cptec.inpe.br/bol_tecnico.shtml>. Acesso em: 20 dez. 2014. 